\title{
Lipid Sorting in Epithelial Cells
}

\author{
Kai Simons, ${ }^{*}$ and Gerrit van Meer $^{\S}$ \\ European Molecular Biology Laboratory, Postfach 10.2209, D-6900 Heidelberg, Federal Republic of Germany, and Department \\ of Cell Biology, Medical School, University of Utrecht, Nicolaas Beetsstraat 22, NL-3511 HG Utrecht, The Netherlands
}

Received February 23, 1988; Revised Manuscript Received March 30, 1988

O ne of the challenges of contemporary cell biology is to unravel how the molecular composition of the different cellular compartments is generated and maintained during the cell cycle. In animal cells most of the efforts have been directed toward the study of how newly synthesized proteins are transported to their correct cellular destinations, whereas the lipids, which make up the framework of the membranes in the cell, have been given much less attention. Lipid biochemistry has remained a fairly esoteric branch of molecular cell biology. This situation is now gradually changing with the discovery of phosphoinositide involvement in signal transduction (Berridge, 1987) and other interesting developments in the lipid field such as covalent attachment of lipids to proteins (Cross, 1987; Pagano \& Sleight, 1985a; Sefton \& Buss, 1987). After years of neglect the interest in the role of lipids in intracellular membrane traffic is also on the rise. Several recent reviews have dealt with this subject in general terms (Pagano \& Sleight, 1985b; Sleight, 1987; Dawidowicz, 1987). Our paper will focus on the generation and maintenance of the different lipid compositions of the two cell surface domains in the polarized cells of simple epithelia. The sorting of newly synthesized surface glycoproteins destined for the two plasma membrane domains has been localized to the trans Golgi network, the exit compartment of the Golgi complex (Griffiths \& Simons, 1986; Simons \& Fuller, 1985; Hughson et al., 1988) (Figure 1). The sorting of newly synthesized sphingolipids en route to the epithelial cell surface also takes place intracellularly in the Golgi complex (van Meer et al., 1987), raising the possibility that protein and lipid sorting are directly connected to each other. Our working hypothesis is that the transport machinery in the trans Golgi network sorts lipids and proteins into common carrier vesicles for delivery to the correct cell surface domain.

The Lipid Composition of Apical and Basolateral Plasma Membrane Domains. The simple epithelia lining the body

\footnotetext{
${ }^{\ddagger}$ European Molecular Biology Laboratory.

8 University of Utrecht.
}

Table I: Lipid Composition of Apical and Basolateral Plasma Membrane Domains of Intestinal Cells ${ }^{a}$

\begin{tabular}{lcc}
\hline & apical (mol \%) & $\begin{array}{c}\text { basolateral } \\
\text { (mol \%) }\end{array}$ \\
\hline glycosphingolipid & $37.1 \pm 9.3$ & $19.4 \pm 12.6$ \\
phospholipid & $32.1 \pm 6.5$ & $52.4 \pm 12.7$ \\
phosphatidylcholine & $8.7 \pm 3.7$ & $31.6 \pm 2.0$ \\
cholesterol & $30.8 \pm 3.1$ & $28.2 \pm 3.0$ \\
cholesterol/phospholipid (mol/mol) & $0.98 \pm 0.13$ & $0.61 \pm 0.21$ \\
\hline \multicolumn{3}{c}{ Comparison of the apical lipid composition with that of the baso- } \\
lateral membrane shows a dramatic increase of glycosphingolipids in \\
the apical membrane at the expense of phosphatidylcholine. The con- \\
centration of the other phospholipids is similar. The values, expressed \\
in mole percent, are the average ( \pm standard deviation) from four in- \\
dependent studies (Forstner et al., 1968; Douglas et al., 1972; Kawai et \\
al., 1974; Brasitus \& Schachter, 1980). \\
\hline
\end{tabular}

cavities are composed of a single layer of polarized cells. The apical plasma membrane domains of the cells line the lumen of the cavity and the basolateral cell surface faces the underlying extracellular matrix and the blood supply (Rodriguez-Boulan, 1983; Simons \& Fuller, 1985). These two plasma membrane domains have different protein and lipid compositions. Each cell in the layer is linked to its neighbors by intercellular junctions including the tight junctions that form the permeability barrier between the cells (Diamond, 1977). The tight junctions also define the boundary between the apical and the basolateral membrane domains.

The distribution of the various lipid classes in the two surface domains has been most extensively studied in rodent intestinal epithelia (Forstner et al., 1968; Douglas et al., 1972; Forstner \& Wherrett, 1973; Kawai et al., 1974; Brasitus \& Schachter, 1980; Chapelle \& Gilles-Baillien, 1983). Due to its specialized microvillar structure the brush border (apical) membrane can be separated from the basolateral membrane. Studies on the purified membrane fractions have revealed that there are no qualitative differences in the lipid compositions between domains. However, the quantitative differences are substantial. The brush border membranes have a glycosphingolipid: phospholipid:cholesterol ratio of about 1:1:1. The high gly- 


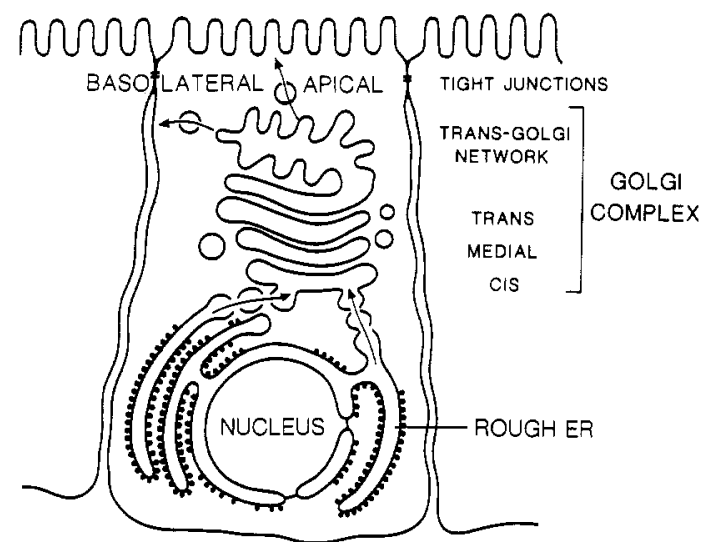

FIGURE 1: Schematic model for the sorting of apical and basolateral viral glycoproteins in MDCK cells. The proteins are synthesized in the endoplasmic reticulum, transported through the Golgi stack (cis, medial, and trans), and finally sorted from each other into separate membrane vesicles in the trans Golgi network. The apical vesicles fuse with the apical membrane to deliver their "cargo", and the basolateral vesicles do the same at the basolateral membrane.

colipid content in the apical membrane is accompanied by a low percentage of phosphatidylcholine (Table I). This is an unusual plasma membrane lipid composition. In contrast, the basolateral membrane has a lipid composition similar to that of plasma membranes of unpolarized cells (Renkonen et al., 1972). The predominant lipid is phosphatidylcholine while the glycosphingolipids constitute only a small fraction of the total lipids. Although the cholesterol:phospholipid ratios are very different, the concentration of cholesterol expressed as mole percent of the total membrane lipids is identical in the brush border and in the basolateral membranes [see van Meer (1988)].

The lipid compositions of apical and basolateral membranes in other simple epithelia, although not as thoroughly studied as for intestinal cells, show similar trends (Stubbs et al., 1979; Hise et al., 1984; Molitoris \& Simon, 1985; Carmel et al., 1985). This is also true for Madin-Darby canine kidney (MDCK) cells grown in culture. The lipid analysis was not performed on the isolated MDCK apical and basolateral membranes but instead on enveloped viruses, budding through either the apical or the basolateral membranes of infected MDCK cells (van Meer \& Simons, 1982, 1986). The apical influenza virus had a glycosphingolipid to phospholipid ratio of close to 1 (G. Hansson, G. van Meer, and K. Simons, unpublished results). The phosphatidylcholine content was low as observed for intestinal brush border membranes. Other studies have shown that MDCK cells as well as other kidney epithelia have a high glycosphingolipid content (Houghland et al., 1979; Spiegel et al., 1985; Hansson et al., 1986; Niimura \& Ishizuka, 1986; Nichols et al., 1986a,b), which is concentrated in the apical plasma membrane domain (Zalc et al., 1978; Turner et al., 1985; Nichols et al., 1987; Hansson et al., 1986). Different strains of MDCK cells exist (Richardson et al., 1981) that have different glycosphingolipid compositions (Hansson et al., 1986; Nichols et al. 1986b). Of the total glycosphingolipid content strain I cells express $56 \%$ glucosylceramide, $6 \%$ galactosylceramide, and members of the neolacto series including a blood group B like pentaglycosylceramide (Hansson, submitted for publication), whereas strain II cells express $28 \%$ glucosylceramide, $16 \%$ galactosylceramide, and more complex members of the globo series with the Forssman antigen as the major species $(21 \%)$. There is also a ricin-resistant MDCK cell strain (Meiss et al., 1982) that has a genetic defect in UDP-galactose uptake into the Golgi complex and cannot galactosylate glycoproteins and glycolipids (A. Brändli, G. Hansson, E. Rodriguez-Boulan, and K. Simons, in preparation). In these cells, about $90 \%$ of the glycosphingolipids are made up to glucosylceramide.

The high apical content of glycolipids may serve to stabilize the membrane (Pascher, 1976; Curatolo, 1987a,b). The apical side of the epithelium faces the external environment where ionic and other conditions vary to a much higher extent than in the internal milieu. In the intestine, for instance, the brush border membrane must protect the cells against lipases and bile salt detergents. Glycosphingolipids are uniquely suited for this stabilizing function because they can form intermolecular hydrogen bonds between the glycosyl head groups, the amide, and the hydroxyl groups of the sphingosine base and of the hydroxy fatty acid (Pascher, 1976). To a lesser extent also sphingomyelin has this capacity to associate by intermolecular hydrogen bonds due to its ceramide constituent. The network of interlipid hydrogen-bonding ties the sphingolipids into a self-associating layer in which the individual lipids show a restricted mobility in both the gel and liquid-crystalline states (Thompson \& Tillack, 1985; Curatolo, 1987a; Boggs, 1987). Fluorescence polarization and other methods have demonstrated that the intestinal and renal brush border membranes exhibit a much higher microviscosity than that of the basolateral membrane (Brasitus \& Schachter, 1980; Hauser et al., 1982; Le Grimellec et al., 1983; Molitoris \& Hoilien, 1987). Karlsson (1982) has suggested that there is a correlation between the number of free hydroxyls on the sphingosine base and fatty acids in sphingolipids and the degree of chemical and physical stress to which the epithelium is exposed. An increase in the number of ceramide hydroxyl groups may contribute to the hydrogen-bonding network, stabilizing the membranes. This extensive intermolecular hydrogen-bonding capacity is a characteristic feature that distinguishes sphaingolipids from the major lipid family in animal cells, the glycerolipids. These cannot form interlipid hydrogen bonds between their diglyceride moieties. The ester and ether groups can only function as hydrogen-bond acceptors, not as donors.

Sphingolipid Sorting. Glycosphingolipids are synthesized in the Golgi complex of animal cells and so must be delivered preferentially to the apical membrane of epithelial cells to achieve their polarized cell surface distribution. Two routes are potentially available for delivery, either by monomeric diffusion across the cytosol or by vesicular carriers.

Recent studies suggest that vesicular transport is involved in polarized delivery (van Meer et al., 1987). These studies were based on a fluorescent ceramide analogue, introduced by Lipsky and Pagano (1983, 1985a,b). These authors showed that [ $N$-(7-nitro-2,1,3-benzoxadiazol-4-yl)amino]caproyl]sphingosine (NBD-ceramide), which had been partitioned into the plasma membrane of fibroblasts at $2^{\circ} \mathrm{C}$, flipped across the plasma membrane bilayer to the cytoplasmic side and distributed into all the intracellular membranes. When the temperature was raised to $37^{\circ} \mathrm{C}$, the fluorescence accumulated in the Golgi complex, apparently as a result of the conversion of the ceramide into NBD-sphingomyelin and NBDglucosylceramide. The addition of phosphocholine and glucosyl head groups prevented flipping across the bilayer and trapped the metabolites on the luminal side of the Golgi complex. From there the NBD-sphingomyelin and -glucosylceramide were found to move to the plasma membrane. The movement to the cell surface could be quantitated by extracting the fluorescent lipids from the plasma membrane with exogenous liposomes or by the addition of serum albumin. This extraction of the fluorescent ceramide analogues is possible because their modified hydrophobic backbone makes them partially water 
soluble. Preferential delivery of the NBD-glucosylceramide to the apical membrane in filter-grown MDCK cells could be demonstrated by quantitating the movement of the metabolized fluorescent sphingolipids (van Meer et al., 1987). After conversion of NBD-ceramide to NBD-sphingomyelin and glucosylceramide, the fluorescent sphingomyelin analogue was found to be delivered in about equal amounts to the apical and the basolateral membranes. In contrast, the delivery of NBD-glucosylceramide was polarized and 2-3-fold more was transported to the apical side than to the basolateral surface. The experimental conditions ensured that the preferential delivery of glucosylceramide to the apical membrane was the result of an intracellular sorting event. The expected polarized distribution was achieved in the transport step that followed sorting.

Preliminary evidence in perforated MDCK cells (Simons \& Virta, 1987) suggests that NBD-sphingolipid transport from the Golgi to the cell surface occurs by vesicular carriers. Holes can be introduced into the apical membrane by peeling off parts of the membrane attached to a nitrocellulose filter. In the presence of ATP the perforated MDCK cells extruded fluorescent vesicles from the Golgi complex into the surrounding medium (M. Bennett, A. Wandinger-Ness, and K. Simons, in preparation). The fluorescent sphingolipids in these putative carrier vesicles were located on the luminal side since these lipids could not be extracted by serum albumin added to the perforated cells.

The Asymmetric Distribution of Lipids in Epithelial Plasma Membranes. Two additional striking observations were made during the course of NBD-lipid delivery to the cell surface in intact MDCK cells (van Meer et al., 1987). First, the cell surface fluorescence could be almost completely extracted by the addition of serum albumin. This is evidence that, after fusion of the vesicular carrier with the plasma membrane, the NBD-sphingomyelin and -glucosylceramide resided in the exoplasmic leaflet. Second, application of the serum albumin to the apical side resulted in removal of only apical fluorescence; the basolateral fluorescence was not affected. Conversely, extraction from the basolateral side depleted only the basolateral NBD-sphingomyelin and -glucosylceramide.

These observations confirm previous studies on the permeability characteristics of epithelial tight junctions. Experiments using different lipid probes (Dragsten et al., 1981, 1982), rhodaminyldioleylphosphatidylethanolamine (van Meer \& Simons, 1986) and the ganglioside $\mathrm{GM}_{1}$ (Spiegel et al., 1985), have shown that the tight junctions form a fence that prevents lipid molecules in the exoplasmic leaflets from diffusing across the boundary between the apical and the basolateral membranes. More surprisingly, these studies have demonstrated that lipid molecules introduced into the cytoplasmic leaflet of the apical membrane can freely diffuse across the tight junction to the basolateral side. Thus, the tight junction appears to function as a fence immersed halfway into the lipid bilayer preventing passage in the exoplasmic leaflet but allowing diffusion in the cytoplasmic leaflet.

A consequence of this peculiar arrangement is that the lipids residing in the cytoplasmic leaflet of the apical and the basolateral membranes should be identical. The lipid differences between the domains have to be restricted to the exoplasmic lipids. Plasma membrane glycosphingolipids are generally known to be localized in the exoplasmic leaflet (Gahmberg \& Hakomori, 1973; Thompson \& Tillack, 1985). Since the apical glycolipid:phospholipid ratio is close to 1 , this leaves little room for phospholipids on the exoplasmic side (except for sphingomyelin, which should reside here on the basis of the behavior of the NBD-sphingomyelin). In fact, such an arrangement is compatible with studies on phospholipid asymmetry that showed that most of the brush border phospholipids were not accessible to reagents from the outside (Barsukov et al., 1986). Subtracting the apical phospholipids (mostly phosphatidylethanolamine, -serine, and -inositol) from the total basolateral phospholipids should, therefore, give an estimate of the distribution of the individual phospholipid classes across the bilayer of the basolateral membrane. For the two major phospholipids this leads to $65-90 \%$ of the phosphatidylethanolamine in the cytoplasmic leaflet and, conversely, 75-90\% of the phosphatidylcholine in the exoplasmic leaflet. This transbilayer distribution (including the exoplasmic localization of sphingomyelin) of the phospholipids corresponds to the well-established rules for phospholipid asymmetry in plasma membranes: choline-containing lipids mostly exoplasmic and amino-containing lipids cytoplasmic (Bretscher, 1972; Bretscher \& Raff, 1975; Op den Kamp, 1979). These findings strengthen the characterization of the basolateral membrane as more or less equivalent to other cellular plasma membranes facing the internal milieu, whereas the apical membrane is the epithelial specialization designed as a shield against the external world.

Lipid asymmetry appears to be an important attribute of plasma membranes. Several studies have shown that ATPdependent cell surface "flippases" exist that translocate phosphatidylethanolamine and phosphatidylserine but not phosphatidylcholine or sphingomyelin from the exoplasmic to the cytoplasmic leaflet (Seigneuret \& Devaux, 1984; Daleke \& Huestis, 1985; Sleight \& Pagano, 1985; Tilley et al., 1986; Zachowski et al., 1986; Martin \& Pagano, 1987). The asymmetry of phospholipids seems to be generated during phospholipid synthesis in the endoplasmic reticulum by another class of flippases that move phosphatidylcholine from its site of synthesis on the cytoplasmic leaflet of the bilayer to the exoplasmic (luminal) side (Bishop \& Bell, 1985; Backer \& Dawidowicz, 1987). NBD-sphingomyelin synthesis takes place on the luminal side of the Golgi complex (Lipsky \& Pagano, $1985 a)$ so that no flippase is necessary to achieve the exoplasmic location of this choline-containing phospholipid. Little more is known about the transbilayer distribution of lipids in the different intracellular compartments connected by vesicular carriers. However, if the generation of plasma membrane lipid asymmetry starts in the endoplasmic reticulum and continues in the Golgi complex, then it seems likely that lipid asymmetry is maintained during intracellular membrane traffic. One reason for this might be that lipid asymmetry plays a role in membrane sorting, as we will propose later, and that not only proteins but also lipids are transported from the endoplasmic reticulum to the cell surface in the vesicular carriers connecting the intermediary stations. Net transport across the cytosol in monomeric form by phospholipid-exchange proteins cannot be excluded at present, but we favor vesicular transport because this mechanism would simplify the interpretation of the available data [see, however, Sleight and Pagano (1983) and Kaplan and Simoni (1985)].

Lipid Sorting during Transcytosis. The tight junctions are not sufficient to maintain the different lipid compositions of the exoplasmic leaflets of the apical and the basolateral membranes. Epithelial cells continuously transport membrane by vesicular carriers between the apical and the basolateral side (Mostov \& Simister, 1985). The extent of this transcytosis has been estimated in filter-grown MDCK cells with fluidphase markers (von Bonsdorff et al., 1985). Assuming that 
the vesicles responsible for transcytosis are $100 \mathrm{~nm}$ in diameter, the apical membrane would internalize the equivalent of half of its surface area in about $60 \mathrm{~min}$. The magnitude of this membrane traffic requires specific mechanisms to prevent intermixing of the apical and the basolateral lipids (and proteins) during transcytosis. Membrane proteins undergoing transcytosis seem to use the same carrier vesicles as endocytosed ligands do and are delivered from the plasma membrane domain to the endosomes. Exactly where in the endocytotic pathway the transcytotic carrier vesicles are formed is not yet known. The transcytotic route seems not to intersect with the biosynthetic transport routes (endoplasmic reticulum or Golgi complex) (Abrahamson \& Rodewald, 1981; Geuze et al., 1984; Pesonen et al., 1984a,b). Therefore, biosynthetic and transcytotic soring cannot take place in the same intracellular site. Lipid sorting during transcytosis occurs either during internalization from the cell surface or inside the cell in the endosomes.

Mechanism of Epithelial Lipid Sorting. Our data suggest that the site of biosynthetic sphingolipid sorting is the Golgi complex. It is tempting to postulate that newly synthesized proteins and lipids destined for the epithelial cell surface are sorted in the trans Golgi network and transported in common carrier vesicles to either the apical or the basolateral cell surface. There is no direct evidence linking lipid and protein sorting, but there is some support for common behavior. Delivery of both sphingolipids and proteins from the Golgi complex is arrested by a temperature block of $20^{\circ} \mathrm{C}$ (Matlin \& Simons, 1984; Pfeiffer et al., 1985; van Meer et al., 1987). After the temperature is returned to $37^{\circ} \mathrm{C}$, the accumulated NBD-lipids and the surface proteins leave the Golgi and appear either on the apical or on the basolateral side with approximately the same kinetics.

The available data on phospholipid and cholesterol movement to the cell surface are controversial (Pagano \& Sleight, 1985b; Sleight, 1987; Dawidowicz, 1987). In the only studies so far on simple epithelia, Molitoris and Simon (1986) concluded that the various phospholipid classes are incorporated with different rates into the apical and basolateral membranes of renal proximal tubule cells from their sites of synthesis. However, a mechanistic interpretation of the data is complicated by the contamination of the plasma membrane preparations by intracellular membranes and the labeling conditions.

The sorting event in the trans Golgi network need not be specific in both the apical and the basolateral directions. It is possible that only one direction is mediated by specific recognition of molecules to be transported (the signal-mediated pathway) and that the other route includes molecules in transit without specific signal recognition (the default pathway) (Pfeffer \& Rothman, 1987). For apical and basolateral membrane proteins, no conclusive answer is available yet, although several attempts have been made to localize the protein signals mediating sorting (Gonzalez et al., 1987; Jones et al., 1985; McQueen et al., 1986, 1987; Mostov et al., 1986, 1987; Puddington et al., 1987; Roman \& Garoff, 1986; Roth et al., 1987). One clue might be the tight exclusion of basolateral proteins from the apical side in MDCK cells (Fuller \& Simons, 1986), whereas the converse is not true (Balcarova-Ständer et al., 1984; Pfeiffer et al., 1985). A small fraction of apical proteins are "missorted" to the basolateral side, possibily because the basolateral route operates by default. Biosynthetic protein transport from the Golgi to the fibroblast cell surface has been postulated to be a default pathway (Wieland et al., 1987). The basolateral route could be the

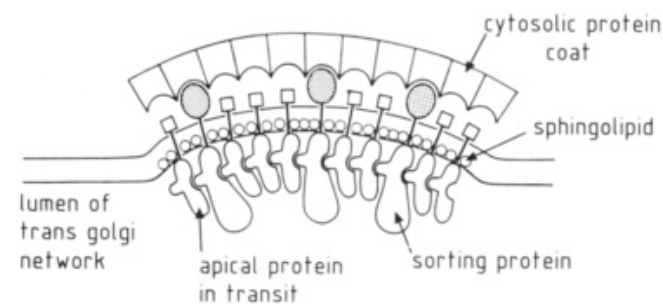

FIGURE 2: Schematic diagram of the proposed apical precursor microdomain in the membrane of the trans Golgi network. The sphingolipids are clustered in the luminal leaflet of the bilayer. The putative sorting proteins form a surface on the cytosolic side, complementary to a cytosolic protein coat that fixes the domain spatially. The curving of the membrane into a vesicle is assumed to result from the structure of the coat protein [see Simons and Fuller (1987)]. The postulated specific interactions with the glycosphingolipids are not included in the diagram. The apical proteins are assumed to interact with each other and with the sorting proteins on the luminal side. The cytosolic domains of the apical proteins are probably not involved in sorting since these are usually short (Simons \& Fuller, 1985), and in some cases the proteins do not span the membrane because they are attached by phosphatidylinositol lipid tails to the bilayer [see Schäli et al. (1984), Takesue et al. (1986), and Cross (1987)].

fibroblast homologue. Sorting in the apical direction would be signal-mediated and be specific for simple epithelia. In more complicated epithelial tissues such as liver, the situation is different. Each hepatocyte has several apical poles lining the bile canaliculi. Bartles et al. (1987) have shown that apical proteins are not sorted in the trans Golgi network. There seems to be no apical route from the Golgi complex to the apical membrane in hepatocytes. Instead, apical proteins are delivered to the basolateral membrane from where they are sorted to the apical side. The simplest interpretation of these findings is that the basolateral transport vesicles carry both apical and basolateral proteins. The apical sorting machinery is lacking from the trans Golgi network in hepatocytes.

In MDCK cells specificity in the apical direction might be aided by glycosphingolipid-protein interactions. Figure 2 illustrates one schematic model. Sphingolipid clustering in the luminal (exoplasmic) leaflet of the trans Golgi network forms the budding site for an apical membrane vesicle. The self-association could be mediated by interlipid hydrogen bonding. This asymmetric sphingolipid microdomain could be the starting point for inclusion of associating apical proteins, which bind directly to the glycosphingolipids or indirectly via interactions to a transmembrane sorting protein. Such a bridging protein should bind to both glycosphingolipid and the apical proteins. Moreover, as depicted in Figure 2, this protein is assumed to have another function. Its cytosolic domain interacts with a cytosolic protein coat to induce the curvature leading to vesiculation. According to this model exclusion of glycerolipids in the exoplasmic leaflet could result from their inability to form interlipid hydrogen bonds with the sphingolipids. The basolateral transport vesicles are predicted to form from the membrane regions depleted on apical components, and these should, therefore, be enriched in phosphatidylcholine as a consequence of lipid asymmetry. The asymmetry of the lipids facilitates the lateral separation of the apical and the basolateral precursor domains in the trans Golgi network. Sorting would, according to this view, be the formation of microdomains mimicking the properties of the membranes of their destination.

This hypothesis makes several predictions that can be tested. First, there should be specific interactions between glycosphingolipids and apical proteins or between glycosphingolipids and the putative bridging protein. Second, in order for exclusion of phosphatidylcholine to occur, the luminal leaflet of 
the membrane segment that forms the apical transport vesicle has to be almost covered by sphingolipids. The sphingolipid to phospholipid ratio of the apical transport vesicles would depend on the size of the vesicle; the larger the vesicle the nearer the ratio between the surface areas of the luminal and the cytoplasmic leaflets will be to 1 . Furthermore, if sphingolipid clustering in the trans Golgi network were a prerequisite for apical delivery, then presumably sphingolipid recycling between the apical membrane and the trans Golgi would be necessary to replenish the sphingolipids lost in each vesiculation event. It seems unlikely that sufficient sphingolipid can be provided by synthesis. However, no data exist on apical glycosphingolipid turnover.

The proposed sorting mechanism embodies two important features. First, a lateral and asymmetric separation of sphingolipids and glycerolipids is envisaged as the first event in the sorting process. The formation of lipid domains in cellular membranes has long been postulated and experimentally substantiated (Karnovsky et al., 1982; Thompson et al., 1986), but no convincing physiological function has yet been attributed to this propensity of lipids. Second, specific interactions between glycosphingolipids and proteins have to occur to localize the lipid and the protein cargo into the same apical membrane precursor. The apical proteins in transit could be included by diffusion-mediated trapping (McCloskey \& Poo, 1984) by binding either to glycosphingolipids, to a bridging protein, or to both.

Further work will prove or disprove this sorting mechanism. Whatever the outcome, we believe that intracellular protein traffic cannot be understood apart from lipid traffic.

\section{ACKNOWLEDGMENTS}

We thank Mark Bennett, Andrê Brändli, Jean Davoust, and Peter Walter for a critical reading of the text and Anne Walter for typing the manuscript.

\section{REFERENCES}

Abrahamson, D. R., \& Rodewald, R. (1981) J. Cell Biol. 91, 270-280.

Backer, J. M., \& Dawidowicz, E. A. (1987) Nature (London) 327, 341-343.

Balcarova-Ständer, J., Pfeiffer, S. E., Fuller, S. D., \& Simons, K. (1984) EMBO J. 3, 2687-2694.

Barsukov, L. I., Bergelson, L. D., Spiess, M., Hauser, H., \& Semenza, G. (1986) Biochim. Biophys. Acta 862, 87-99.

Bartles, J. R., Feracci, H. M., Stieger, B., \& Hubbard, A. L. (1987) J. Cell Biol. 105, 1241-1251.

Berridge, M. J. (1987) Annu. Rev. Biochem. 56, 159-194.

Bishop, W. R., \& Bell, R. M. (1985) Cell (Cambridge, Mass.) 42, 51-60.

Boggs, J. M. (1987) Biochim. Biophys. Acta 906, 353-404.

Brasitus, T. A., \& Schachter, D. (1980) Biochemistry 19, 2763-2769.

Bretscher, M. S. (1972) J. Mol. Biol. 71, 523-528.

Bretscher, M. S., \& Raff, M. C. (1975) Nature (London) 258, 43-49.

Carmel, G., Rodrigue, F., Carrière, S., \& Le Grimellec, C. (1985) Biochim. Biophys. Acta 818, 149-157.

Chapelle, S., \& Gilles-Baillien, M. (1983) Biochim. Biophys. Acta 753, 269-271.

Cross, G. A. M. (1987) Cell (Cambridge, Mass.) 48, 179-181. Curatolo, W. (1987a) Biochim. Biophys. Acta 906, 111-136. Curatolo, W. (1987b) Biochim. Biophys. Acta 906, 137-160.

Daleke, D. L., \& Huestis, W. H. (1985) Biochemistry 24, 5406-5416.

Dawidowicz, E. A. (1987) Annu. Rev. Biochem. 56, 43-61.
Diamond, J. M. (1977) Physiologist 20, 10-18.

Douglas, A. P., Kerley, R., \& Isselbacher, K. J. (1972) Biochem. J. 128, 1329-1338.

Dragsten, P. R., Blumenthal, R., \& Handler, J. S. (1981) Nature (London) 294, 718-722.

Dragsten, P. R., Handler, J. S., \& Blumenthal, R. (1982) Fed. Proc., Fed. Am. Soc. Exp. Biol. 41, 48-53.

Forstner, G. G., \& Wherrett, J. R. (1973) Biochim. Biophys. Acta 306, 446-459.

Forstner, G. G., Tanaka, K., \& Isselbacher, K. J. (1968) Biochem. J. 109, 51-59.

Fuller, S. D., \& Simons, K. (1986) J. Cell Biol. 103, 1767-1779.

Gahmberg, C. G., \& Hakomori, S. (1973) J. Biol. Chem. 248, 4311-4317.

Geuze, J. J., Slot, J. W., Strous, G. J. A. M., Peppard, J., von Figura, K., Hasilik, A., \& Schwartz, A. L. (1984) Cell (Cambridge, Mass.) 37, 195-204.

Gonzalez, A., Rizzolo, L., Rindler, M., Adesnik, M., Sabatini, D. D., \& Gottlieb, T. (1987) Proc. Natl. Acad. Sci.U.S.A. 84, 3738-3742.

Griffiths, G., \& Simonis, K. (1986) Science (Washington, D.C.) $234,438-443$.

Hansson, G. C., Simons, K., \& van Meer, G. (1986) EMBO J. 5, 483-489.

Hauser, H., Gains, N., Semenza, G., \& Spiess, M. (1982) Biochemistry 21, 5621-5628.

Hise, M. K., Mantulin, W. W., \& Weinman, E. J. (1984) Am. J. Physiol. 247, F434-F439.

Houghland, A. E., Gaush, C. R., \& Mayberry, W. R. (1979) Biochem. J. 177, 311-317.

Hughson, E., Wandinger-Ness, A., Gausepohl, H., Griffiths, G., \& Simons, K. (1988) in The molecular biology and infections diseases. Centenary Symposium of the Pasteur Institute (Schwartz, M., Ed.) Elsevier, Amsterdam (in press).

Jones, L. V., Compans, R. W., Davis, A. R., Bos, T. J., \& Nayak, D. P. (1985) Mol. Cell. Biol. 5, 2181-2189.

Kaplan, M. R., \& Simoni, R. D. (1985) J. Cell Biol. 101, 441-445.

Karlsson, K. A. (1982) in Biological Membranes (Chapman, D., Ed.) Vol. 4, pp 1-74, Academic, New York.

Karnovsky, M. J., Kleinfeld, A. M., Hoover, R. L., \& Klausner, R. D. (1982) J. Cell Biol. 94, 1-6.

Kawai, K., Fujita, M., \& Nakao, M. (1974) Biochim. Biophys. Acta 369, 222-233.

Le Grimellec, C., Carrière, S., Cardinal, J., \& Giocondi, M.-C. (1983) Am. J. Physiol. 245, F227-F231.

Lipsky, N. G., \& Pagano, R. E. (1983) Proc. Natl. Acad. Sci. U.S.A. 80, 2608-2612.

Lipsky, N. G., \& Pagano, R. E. (1985a) J. Cell Biol. 100, 27-34.

Lipsky, N. G., \& Pagano, R. E. (1985b) Science (Washington, D.C.) $228,745-747$.

Martin, O. C., \& Pagano, R. E. (1987) J. Biol. Chem. 262, 5890-5898.

Matlin, K. S., \& Simons, K. (1984) J. Cell Biol. 99, 2131-2139.

McCloskey, M., \& Poo, M. (1984) Int. Rev. Cytol. 87, 19-81.

McQueen, N. L., Nayak, D. P., Stephens, E. B., \& Compans, R. W. (1986) Proc. Natl. Acad. Sci. U.S.A. 83, 9318-9322.

McQueen, N. L., Nayak, D. P., Stephens, E. B., \& Compans, R. W. (1987) J. Biol. Chem. 262, 16233-16240.

Meiss, H. K., Green, R. F., \& Rodriguez-Boulan, E. (1982) Mol. Cell. Biol. 2, 1287-1294. 
Molitoris, B. A., \& Simon, F. R. (1985) J. Membr. Biol. 83, 207-215.

Molitoris, B. A., \& Simon, F. R. (1986) J. Membr. Biol. 94, 47-53.

Molitoris, B. A., \& Hoilien, C. (1987) J. Membr. Biol. 99, 165-172.

Mostov, K. E., \& Simister, N. E. (1985) Cell (Cambridge, Mass.) 43, 389-390.

Mostov, K. E., du Bruyn Kops, A., \& Deitcher, D. L. (1986) Cell (Cambridge, Mass.) 47, 359-364.

Mostov, K. E., Breitfeld, P., \& Harris, J. M. (1987) J. Cell Biol. 105, 2031-2036.

Nichols, G. E., Borgman, C. A., \& Young, W. W., Jr. (1986a) Biochem. Biophys. Res. Commun. 138, 1163-1169.

Nichols, G. E., Lovejoy, J. C., Borgman, C. A., Sanders, J. M., \& Young, W. W., Jr. (1986b) Biochim. Biophys. Acta $887,1-12$.

Nichols, G. E., Shiraishi, T., Allietta, M., Tillack, T. W., \& Young, W. W., Jr. (1987) Biochim. Biophys. Acta 930, 154-166.

Niimura, Y., \& Ishizuka, I. (1986) J. Biochem. (Tokyo) 100, 825-835.

Op den Kamp, J. A. F. (1979) Annu. Rev. Biochem. 48, 47-71.

Pagano, R. E., \& Sleight, R. G. (1985a) Trends Biochem. Sci. (Pers. Ed.) 10, 421-425.

Pagano, R. E., \& Sleight, R. G. (1985b) Science (Washington, D.C.) 229, 1051-1057.

Pascher, I. (1976) Biochim. Biophys. Acta 455, 433-451.

Pesonen, M., Ansorge, W., \& Simons, K. (1984a) J. Cell Biol. 99, 796-802.

Pesonen, M., Bravo, R., \& Simons, K. (1984b) J. Cell Biol. 99, 803-809.

Pfeffer, S. R., \& Rothman, J. E. (1987) Annu. Rev. Biochem. 56, 829-852.

Pfeiffer, S., Fuller, S. D., \& Simons, K. (1985) J. Cell Biol. $101,470-476$

Puddington, L., Woodgett, C., \& Rose, J. K. (1987) Proc. Natl. Acad. Sci. U.S.A. 84, 2756-2760.

Renkonen, O., Gahmberg, C. G., Simons, K., \& Kääriäinen, L. (1972) Biochim. Biophys. Acta 255, 66-78.

Richardson, J. C. W., Scalera, V., \& Simmons, N. L. (1981) Biochim. Biophys. Acta 673, 26-36.

Rodriguez-Boulan, E. (1983) Mod. Cell Biol. 1, 119-170.

Roman, L. M., \& Garoff, H. (1986) J. Cell Biol. 103, 2607-2618.

Roth, M. G., Gundersen, D., Patil, N., \& Rodriguez-Boulan, E. (1986) J. Cell Biol. 104, 769-782.
Schäli, C., Vaughn, D. A., \& Fanestil, D. D. (1984) Biochim. Biophys. Acta 769, 277-283.

Schwartz, A. L., \& Rup, D. (1983) J. Biol. Chem. 258, 11249-11255.

Sefton, B. M., \& Buss, J. E. (1987) J. Cell Biol. 104, 1449-1453.

Seigneuret, M., \& Devaux, P. F. (1984) Proc. Natl. Acad. Sci. U.S.A. $81,3751-3755$.

Simons, K., \& Fuller, S. D. (1985) Annu. Rev. Cell Biol. 1, 243-288.

Simons, K., \& Fuller, S. (1987) in Biological Organization: Macromolecular interactions at high resolution (Burnett, R. M., \& Vogel, H. J., Ed.) pp 139-150, Academic, New York.

Simons, K., \& Virta, H. (1987) EMBO J. 6, 2241-2247.

Sleight, R. G. (1987) Annu. Rev. Physiol. 49, 193-208.

Sleight, R. G., \& Pagano, R. E. (1985) J. Biol. Chem. 260 , 1146-1154.

Spiegel, S., Blumenthal, R., Fishman, P. H., \& Handler, J. S. (1985) Biochim. Biophys. Acta 821, 310-318.

Stubbs, C. D., Ketterer, B., \& Hicks, R. M. (1979) Biochim. Biophys. Acta 558, 58-72.

Takesue, Y., Yokota, K., Nishi, Y., Taguchi, R., \& Ikezawa, H. (1986) FEBS Lett. 201, 5-9.

Thompson, T. E., \& Tillack, T. W. (1985) Annu. Rev. Biophys. Bioeng. 14, 361-386.

Thompson, T. E., Barenholz, Y., Brown, R. E., Correa-Freire, M., Young, W. W., \& Tillack, T. W. (1986) in Enzymes of lipid metabolism (Freysz, L., Ed.) pp 387-396, Plenum, New York.

Tilley, L., Cribier, S., Roelofson, B., Op den Kamp, J. A. F., \& van Deenen, L. L. M. (1986) FEBS Lett. 194, 21-27.

Turner, R. J., Thompson, J., Sariban-Sohraby, S., \& Handler, J. S. (1985) J. Cell Biol. 101, 2173-2180.

van Meer, G. (1988) Mod. Cell Biol. (in press).

van Meer, G., \& Simons, K. (1982) EMBO J. 1, 847-852. van Meer, G., \& Simons, K. (1986) EMBO J. 5, 1455-1464. van Meer, G., Stelzer, E. H. K., Wijnaendts-van-Resandt, R. W., \& Simons, K. (1987) J. Cell Biol. 105, 1623-1635. von Bonsdorff, C.-H., Fuller, S. D., \& Simons, K. (1985) EMBO J. 4, 2781-2792.

Wieland, F. T., Gleason, M. L., Serafini, T. A., \& Rothman, J. E. (1987) Cell (Cambridge, Mass.) 50, 289-300.

Zachowski, A., Favre, E., Cribier, S., Hervë, P., \& Devaux, P. F. (1986) Biochemistry 25, 2585-2590.

Zalc, B., Helwig, J. J., Ghandour, M. S., \& Sarlieve, L. (1978) FEBS Lett. 92, 92-96. 